\title{
Energy Valorization by Continuous Pyrolysis of Straight Vegetable Oils (SVOs)
}

\author{
Abollé Abollé1 ${ }^{*}$, Konan Edmond Kouassi ${ }^{1}$, Henri Planche², Albert Trokourey ${ }^{3}$, \\ Kouassi Benjamin Yao4, Ado Gossan"
}

${ }^{1}$ Unité de Formation et de Recherche-SFA, Université Nangui Abrogoua (UNA), Abidjan, Republic of Côte d'Ivoire

${ }^{2}$ Unité de Chimie et Procédés, Ecole Nationale Supérieure des Techniques Avancées, Paris, France

${ }^{3}$ Unité de Formation et de Recherche-SSMT, Université Houphouët-Boigny (UFHB), Abidjan, Republic of Côte d'Ivoire

${ }^{4}$ Institut National Polytechnique Félix Houphouët-Boigny, Yamoussoukro, Republic of Côte d'Ivoire

Email: *abolle_g@hotmail.com

How to cite this paper: Abollé, A., Kouassi, K.E., Planche, H., Trokourey, A., Benjamin Yao, K. and Gossan, A. (2018) Energy Valorization by Continuous Pyrolysis of Straight Vegetable Oils (SVOs). Green and Sustainable Chemistry, 8, 19-31. https://doi.org/10.4236/gsc.2018.81002

Received: November 15, 2017

Accepted: January 23, 2018

Published: January 26, 2018

Copyright (C) 2018 by authors and Scientific Research Publishing Inc. This work is licensed under the Creative Commons Attribution International License (CC BY 4.0).

http://creativecommons.org/licenses/by/4.0/

\begin{abstract}
Researches have been undertaken to find a form of valorization of the surplus production of vegetable oils in Côte d'Ivoire for their use as a substitute diesel. The first tests of the use of crude oils-diesel blends by the company Palmindustrie faced enormous difficulties. We have therefore undertaken a campaign of pyrolysis of Tropical Straight Vegetable Oils: palm, copra, peanut, cotton, cabbage palm and shea, between $400^{\circ} \mathrm{C}$ and $600^{\circ} \mathrm{C}$ under atmospheric pressure. A silica support was used in co-catalysis either with water or with methylcyclohexane, which is a model compound of cetanes contained in gas oil. This compound has the advantage, unlike the gas oil itself, of not masking the peaks of the pyrolysis recombinates of oils in the chromatograms. The condensed organic phase consists mainly of hydrocarbons including paraffins, olefins, alkylbenzenes and styrenes. The yields of liquid hydrocarbons vary between $72 \%$ and $86 \%$. A comparative study of coke precursors and gas production was carried out. A discussion on the parameters to be considered for a large-scale implementation was undertaken.
\end{abstract}

\section{Keywords}

Straight Vegetable Oils (Palm, Copra, Peanut, Palm Kernel, Cotton and Shea), Hydrocarbons, Coke

\section{Introduction}

The devaluation of the 1994 CFA franc has severely depressed the trade balance, sometimes resulting in a shortage of foreign exchange in developing countries. This situation has aroused interest in research into the use of biomass for energy 
purposes.

During the periods of overproduction, low prices for agricultural products lead to an impoverishment of producers. A technology to quickly switch overproduction of oilseeds on the fuel market would maintain a flat price indexed on diesel. Taking into account the very high tax on petroleum products, a government can decide to impose a much higher oil price on the national level than oil to support its agriculture.

For a country like Côte d'Ivoire, by sacrificing about three thousandth of its tax rent on the total sale of fuels, the government would for example guarantee the producer a price of 250FCFA/liter when the price of palm oil falls to 200FCFA without the consumer feeling the slightest price increase at the pump. So that this surplus of oil can be hoisted to the rank of fuel, the proposed formulation should be perfectly compatible with engines working with petroleum products.

Two ways of converting vegetable oils into fuels are possible: direct route by mixing with gasoil [1] [2], and chemical conversion to hydrocarbons [3]. The first has been implemented several years ago by small companies, especially in North America and France that have captive fleets of vehicles.

The mixture of vegetable oils with diesel, as we have previously done, gives better results when the oil content is lower than $30 \%$, beyond this limit, this practice would become problematic [1]. In any case, the implementation makes users highly dependent on fossil fuels. In addition, results of vegetable oils pyrolysis could be applied to waste oil mills and even to inedible oils such as rubber seeds that have so far been unexploited although produced in large quantities [4]. Most rubber seeds rot under the tree as described by Edmond K. [5].

In this article, we will consider the path of chemical conversion for all these reasons mentioned.

Works on the conversion of vegetable oils into fuel was initiated in the $1920 \mathrm{~s}$ by researchers including Mailhe et al. [6]. They studied the conversion of vegetable oils, fats, and soaps to hydrocarbons. In all these studies, no precise analysis was made of the obtained products.

The first studies of the mechanism reactions were carried out by Laurant et al. [7] who study the cut of the ester function.

Pyrolysis work carried out at the Surface Reactivity Laboratory of the University of Paris VI is mainly oriented in the synthesis of $\mathrm{MoO}_{3} / \gamma-\mathrm{Al}_{2} \mathrm{O}_{3}, \mathrm{Ru} / \mathrm{SiO}_{2}$ and $\mathrm{NiO}-\mathrm{MoO}_{3} / \gamma-\mathrm{Al}_{2} \mathrm{O}_{3}$ as catalysts [8]. Even if the results of their work done at 200 bars seem to be attractive, the conditions are very severe and these catalysts will be out of reach for African farmers. For these reasons, other researchers are now proposing the cracking of vegetable oil mixtures with fuel or fossil heavy residues at atmospheric pressure in the presence of catalysts that are simple to implement, such as zeolites [9].

Our present work of pyrolysis concerns the proposal of a continuous process allowing the transformation of vegetable oils into hydrocarbons. In this tech- 
nique, we use like in our previous works [3], in addition to the silica support either water or the methylcyclohexane in order to reduce the formation of coke contained in the heavy and viscous residue [10], without using hydrogen.

\section{Material and Methods}

\subsection{Material}

\section{1) Biological material}

The different vegetable oils used are the palm, copra, palm kernel, cotton, peanut and shea oil produced in Cote d'Ivoire. Their chemical characteristics are shown in Table 1, and their fatty acid composition summarized in Table 2.

2) Analysis Equipment

For the analysis of pyrolysis results, we have a GC/MS: Gas chromatography

Table 1. Chemical characteristics of used oils.

\begin{tabular}{|c|c|c|c|c|c|c|c|c|}
\hline Chemical index & Units & Palm & Palm SG & Copra & Groundnut & Cotton & Cabbage & Shea \\
\hline Iodine index & $\begin{array}{c}\mathrm{g} \text { of } \\
\mathrm{I}_{2} / 100 \mathrm{~g}\end{array}$ & 65.5 & 60.8 & 11.2 & 96.6 & 112.4 & 20.8 & 32.9 \\
\hline $\begin{array}{l}\text { Saponification } \\
\text { index }\end{array}$ & $\begin{array}{c}\mathrm{mg} \text { of } \\
\mathrm{KOH} / \mathrm{g}\end{array}$ & 195 to 205 & 195 to 2052 & 255 to 267 & 7186 to 196 & 190 to 198 & 246 to 254 & - \\
\hline Peroxide index & $\begin{array}{c}\text { meq } \\
\mathrm{O}_{2} / \mathrm{kg}\end{array}$ & 2.45 & 7.85 & 4.41 & 31.37 & 16.91 & 2.72 & 35.10 \\
\hline Acid index & $\begin{array}{c}\mathrm{mg} \text { of } \\
\mathrm{KOH} / \mathrm{g}\end{array}$ & 14.4 & 67.8 & 3.5 & 3.3 & 2.5 & 9.7 & 18.5 \\
\hline
\end{tabular}

Palme GS: Secondary grade palm oil.

Table 2. Fatty acid compositions of the oils used (in \% mass).

\begin{tabular}{cccccccc}
\hline Fatty acids & Palm & Palm SG & Copra & Cabbage & Groundnut & Shea & Cotton \\
\hline Caprylic & - & - & 7.22 & 7.56 & - & - & - \\
Capric & - & - & 6.96 & 4.08 & - & - & - \\
Lauric & 1.17 & 0.38 & 26.63 & 24.86 & 0.26 & 0.39 & 0.26 \\
Myristic & 2.50 & 1.81 & 19.40 & 17.85 & 0.13 & 0.67 & 2.22 \\
Palmitic & 23.39 & 25.99 & 12.40 & 12.15 & 10.67 & 6.29 & 17.73 \\
Linoleic & 10.12 & 7.69 & 1.02 & 2.34 & 9.18 & 3.29 & 25.59 \\
Oleic & 36.10 & 36.05 & 11.59 & 22.00 & 35.19 & 44.32 & 22.46 \\
Stearic & 11.05 & 12.94 & 5.78 & 6.09 & 7.93 & 39.43 & 6.79 \\
Linolenic & 2.58 & 2.31 & 0.72 & 0.50 & 2.68 & 0.75 & 4.85 \\
Arachidic & 1.67 & 1.26 & - & - & 4.54 & 1.49 & 0.82 \\
Behenic & 0.14 & - & - & - & 6.75 & - & - \\
\% Saturated & 39.92 & 42.36 & 78.39 & 72.59 & 30.27 & 48.27 & 27.82 \\
\hline
\end{tabular}

Source: State thesis of A. Abollé [11]. 
STAR 3400CX coupled to a mass spectrometer: Varian SATURN 4D-GC/MS. The HPCHEM software of Agillent Technology was used for the exploitation of chromatogram.

Furnace programming:

From $40^{\circ} \mathrm{C}$ to $300^{\circ} \mathrm{C}$, a ramp of $4^{\circ} \mathrm{C} / \mathrm{min}$, followed by a plateau at $300^{\circ} \mathrm{C}$ until all the compounds have eluted completely (for $35 \mathrm{~min}$ ). The time required for the complete elution of the compounds which can be vaporized according to these conditions is 100 minutes.

\subsection{Methods}

1) Pyrolysis Unit

Figure 1 gives the block diagram of the pyrolysis unit, the different parts of which are:

- Injection of the load: it is carried out by the pump JASCO PU 980i (Intelligent HPLC pump). The molten oil is aspirated from a $150 \mathrm{ml}$ beaker over

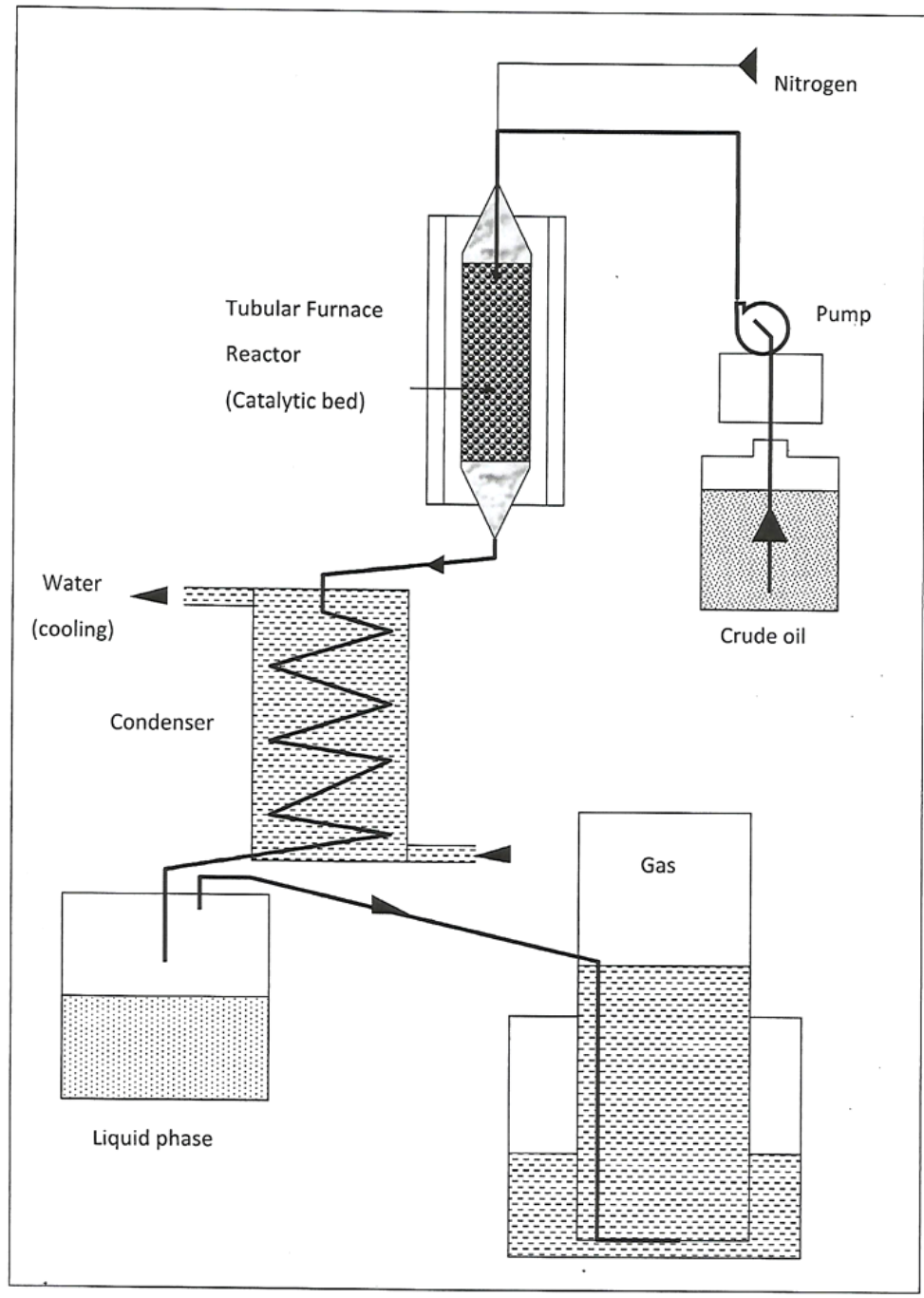

Figure 1. Schematic diagram of continuous pyrolysis. 
a height of $1.5 \mathrm{~m}$ and injected into the reactor. For the injection of the carrier gas, we have a bottle of nitrogen under 200 bars. Extended to about ten bars, the nitrogen allows making tests under pressure of the reactor before the launch of the operation. At the beginning of each manipulation, the pressure will be adjusted close to the atmosphere to initiate the passage of the oil through the catalytic bed.

- Heating and evaporation of the products and reactions in the reactor: the reactor is immersed vertically in a tubular furnace. The pyrolysis reactions take place under the combined effect of catalysts and heat.

Trapping of the condensable products at the reactor outlet: the reactor effluent is condensed. Two phases are then obtained: one liquid and the other gas.

2) Operating protocol

a) Preheating and reactor temperature rise

This operation conditions the life of the heated elements. A too rapid rise in the temperature of the reactor could lead to a rapid deterioration of the latter. The temperature peaks vary between $400^{\circ} \mathrm{C}$ and $600^{\circ} \mathrm{C}$. The tubular furnace temperature used is set at the nominal value $\pm 5^{\circ} \mathrm{C}$.

Moreover, between two manipulations (for the same type of oil), the furnace is left at $400^{\circ} \mathrm{C}$. For some cases, the assembly is done at room temperature to renew the catalytic bed and make a mass balance.

At the beginning of each experiment the preheating temperature is set at $400^{\circ} \mathrm{C}$ for about 15 minutes to dehydrate the silica-loaded catalyst bed by sweeping the latter with nitrogen. This operation permits to better adjust the flow rate of the carrier gas between 10 and 15 minutes.

b) Preheating the load

The load is preheated to a moderate temperature of $60^{\circ} \mathrm{C}$ on a CIMAREC 2 agitator heater plate.

\section{c) Priming the pump}

The pump is first primed with acetone before the preheated oil passes through. Next comes the setting of the flow rate of the oil to which the reactor will be supplied.

d) Obtaining the steady state in the reactor

Once the flow rates have been adjusted, the charge (liquid oil) is injected into the reactor via the oil pump. The low flow rate of the charge ( 0.25 to 0.50 $\mathrm{cm}^{3} / \mathrm{min}$ ) allows rapid thermal stabilization at the nominal temperature in the reactor. When the flow rate of the feedstock and the carrier gas are constant, the steady state in the reactor is reached.

The main parameters governing the pyrolysis conditions of the samples are given in Table 3, the operating pressure being the atmosphere.

\section{Results and Discussion}

\subsection{Mass Balance}

The mass balances are made by pyrolysis. On $100 \mathrm{~g}$ of starting oil, we have the following distribution at the reactor outlet at $550^{\circ} \mathrm{C}$. Table 4 summarizes pyro- 
lysis mass balance.

The proportions of gas are less than $6 \%$ except for secondary grade palm oil where this value reaches that published by Brigdwater [12] who obtains $13 \%$ in the case of rapid pyrolysis corresponding to our temperature conditions. The higher value for the secondary quality palm case could be due to the high proportion of free fatty acid (acid index: 67.8) in this oil. These free fatty acids would have a strong tendency to decompose into light products compared to pure triglycerides. Our previous results [3] showed that water remarkably reduced the proportion of gas.

Table 3. Parameters of pyrolysis carried out.

\begin{tabular}{|c|c|c|c|c|c|}
\hline Oils & Temperature $\left({ }^{\circ} \mathrm{C}\right)$ & $\begin{array}{l}\text { Injection rate } \\
(\mathrm{ml} / \mathrm{min})\end{array}$ & Porosity $\left(\mathrm{cm}^{3}\right)$ & $\begin{array}{l}\text { Oil flow } \\
\left(\mathrm{cm}^{3} / \mathrm{min}\right)\end{array}$ & stay $(s)$ \\
\hline \multirow{4}{*}{ Copra } & 400 & 0.25 & 11 & 19.08 & 34.59 \\
\hline & 450 & 0.25 & 11 & 20.49 & 32.20 \\
\hline & 530 & 0.409 & 11 & 37.24 & 24.16 \\
\hline & 550 & 0.409 & 11 & 37.94 & 23.72 \\
\hline \multirow{5}{*}{ Palm } & 400 & 0.25 & 11 & 15.97 & 41.32 \\
\hline & 500 & 0.409 & 11 & 30.01 & 21.99 \\
\hline & 530 & 0.4 & 11 & 30.49 & 21.64 \\
\hline & 550 & 0.409 & 11 & 32.34 & 20.40 \\
\hline & 600 & 0.35 & 15 & 28.96 & 31.06 \\
\hline \multirow{3}{*}{ Groundnut } & 450 & 0.25 & 11 & 16.01 & 41.20 \\
\hline & 470 & 0.25 & 11 & 16.46 & 40.09 \\
\hline & 500 & 0.25 & 11 & 17.12 & 38.54 \\
\hline \multirow{2}{*}{ Cabbage } & 500 & 0.37 & 15 & 31.22 & 28.82 \\
\hline & 550 & 0.383 & 15 & 34.41 & 26.15 \\
\hline \multirow{2}{*}{ Cotton } & 500 & 0.35 & 15 & 25.45 & 35.36 \\
\hline & 550 & 0.35 & 15 & 26.76 & 33.62 \\
\hline Shea & 550 & 0.37 & 15 & 26.73 & 33.66 \\
\hline
\end{tabular}

Table 4. Pyrolysis mass balance.

\begin{tabular}{cccccc}
\hline Oils & Copra & Palm SG & Shea & Cotton & Cabbage \\
\hline Condensed phase & 96.18 & 84.58 & 86.99 & 93.27 & 91.49 \\
Water & 9.62 & 13.16 & 6.53 & 6.99 & 7.24 \\
organic phase & 86.56 & 72.13 & 80.46 & 86.28 & 84.25 \\
Gaz & 2.87 & & 13.89 & 2.79 & 4.17 \\
Coke & 0.94 & & 1.52 & 3.95 & 4.33 \\
Total & 100.00 & & 100.00 & 100.00 & 100.00 \\
\hline
\end{tabular}


The coke synthesis rates we found are less than 5\% except shea butter oil which gives a rate of $7.05 \%$. Our values are much lower than those of Brigdwater, which obtained more than twice as much as $12 \%$ as a solid residue. French [13] who practiced catalytic pyrolysis of the biomass for the production of biofuel between $400^{\circ} \mathrm{C}$ and $600^{\circ} \mathrm{C}$, obtained between $22 \%$ and $31 \%$ of coke. However, coke synthesis encountered in the use of crude oils in conventional engines in Côte d'Ivoire came mainly from the deposits of gums, combustion residue, on the sensitive organs. To circumvent these difficulties, Hossain et al. [14] proposed that the engine should run first with conventional fuel before the pyrolysis of oil blended with biodiesel.

The pyrolysis of heavy oils in the presence of subcritical water was carried out by Chun-Chun et al. [15] at a temperature far from the rupture of the C-C bond. They concluded that the pyrolysis of heavy oils in water is dominated by an ionic mechanism and that water can be approximated as inert during pyrolysis. However, this result does not conform to ours, which show different conversion rates for the case of the oil without additive and in the case of the water-in-oil emulsion.

\subsection{Study of the Compounds Obtained According to the Saturation Rate of the Oils}

For each starting oil, we calculated the averages of the hydrocarbon compounds formed. These normalized values for all the hydrocarbons give these results grouped together in Table 5.

In a first approximation, the reactor effluents have almost the same proportions of hydrocarbons. We obtain on average:

- 25\% paraffins,

- $60 \%$ of alkenes of which more than $40 \%$ are di-alkenes,

- $12 \%$ alkyl benzene,

- $3 \%$ of styrenes.

This distribution is independent of pyrolysis temperature, oils saturation rate and the conversion rates as we have previously observed [3].

In the second order, when the saturation rate is higher than $60 \%$, the proportion of alkenes decreases sharply. This result is predictable since, at high saturation, there are fewer double bonds responsible for the formation of olefins.

Table 5. Average values of the hydrocarbon compounds (\% mass).

\begin{tabular}{|c|c|c|c|c|c|c|c|}
\hline \multicolumn{2}{|c|}{ Pyrolyzed Oils } & Groundnut & Copra & Palm & Cotton & Cabbage & Shea \\
\hline \multicolumn{2}{|c|}{ Saturation rate } & 33.63 & 84.07 & 47.10 & 31.96 & 74.18 & 54.88 \\
\hline \multirow{4}{*}{ Hydrocarbons } & paraffin & 20.90 & 25.74 & 21.97 & 10.44 & 25.87 & 22.81 \\
\hline & alkenes & 61.70 & 49.78 & 59.96 & 61.32 & 58.00 & 62.09 \\
\hline & alkyl benzene & 11.12 & 16.44 & 15.35 & 21.32 & 12.84 & 12.19 \\
\hline & styrene & 2.95 & 3.11 & 2.72 & 6.92 & 3.30 & 2.91 \\
\hline
\end{tabular}


Unlike cokes precursors which are quasi-constant, the representative curves of paraffins and alkylbenzenes show a gentle growth. This is justified by the fact that the production of paraffins and alkenes are positively correlated with the progression of the pyrolysis reaction because these compounds come directly from the decomposition of the triglycerides composing the crude oils. While paraffins would grow continuously, some of the alkenes would first be transformed into alkylbenzenes, then into styrene and finally into coke. The transformation of alkenes into alkylbenzenes seems to be a faster step in this process.

1) Influence of the conversion rate

In order to determine the influence of hydrocarbon conversion rates on the results obtained, we studied the evolution of the proportions of the compounds as a function of the progress of the reactions. Table 6 gives the evolution of mass proportions of the compounds according to the conversion rate for groundnut and palm oils, and the curves are shown in Figure 2.

If the results corresponding to the low conversion rates (less than 6\%) are not taken into account, the proportions of the various compounds neither correlate with oils saturation degree, nor their distribution in fatty acids.

2) Study of the influence of hydrogen donors: water and methyl-cyclohexane

In order to reduce the proportions of gases, light products and the formation of cokes, we have studied the effect of the hydrogen donors: water and methyl cyclohexane. Table 7 gives the mass proportions of alkyl benzenes compared to those of the styrenes (cokes precursors) for three vegetable oils at different temperatures. The evolutions of these two compounds according to the temperatureare given in Figure 3.

Irrespective of the type of oil, the proportions in styrene are growing with those of alkyl benzenes. This is particularly true when the conversion rate is greater than $4 \%$.

The analysis of the results shows that the addition of methylcyclohexane to the

Table 6. Evolution of the mass proportions of the compounds according to the conversion rate.

Groundnut

\begin{tabular}{ccccc}
\hline Conversion rate (\%) & Styrenes & Alkylbezenes & Paraffins & Alkenes \\
\hline 7.05 & 8 & 13 & 40 & 38 \\
16 & 0.3 & 9 & 21 & 64 \\
37 & 1.5 & 10 & 25 & 63 \\
68 & 3 & 11 & 20 & 64 \\
\hline & & Palm & & \\
\hline Conversion rate (\%) & Styrenes & Alkylbezenes & Paraffins & Alkenes \\
\hline 3.5 & 0 & 42 & 27 & 32 \\
27 & 1 & 17 & 12 & 69 \\
56.5 & 2 & 12 & 20 & 60 \\
60.05 & 4 & 15 & 13 & 58 \\
\hline
\end{tabular}




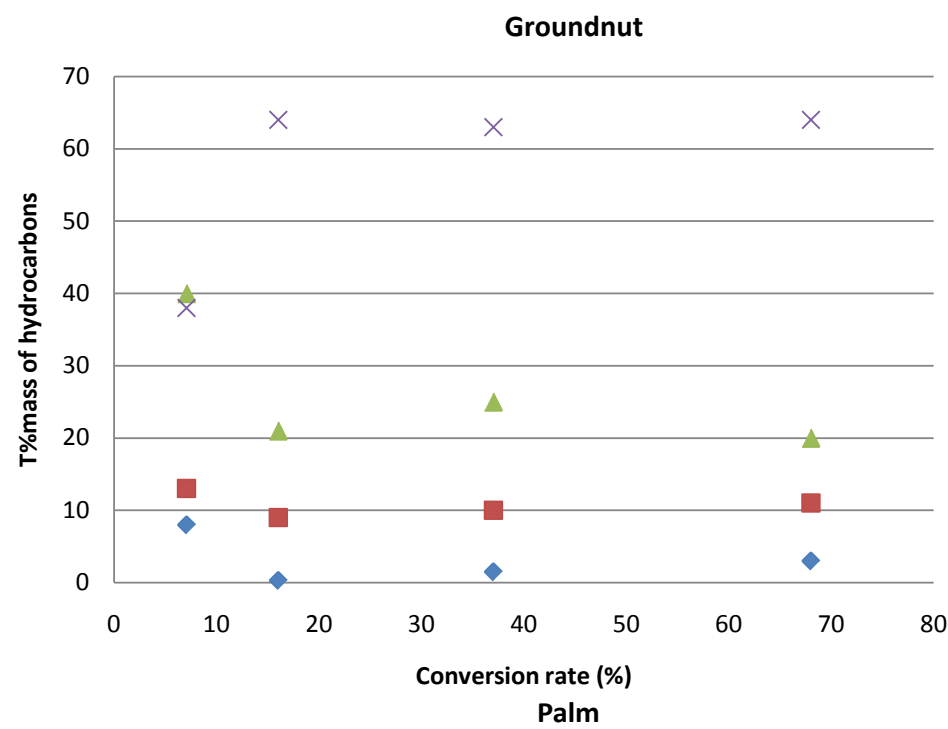

Styrenes
Alkybezenes

$\triangle$ Paraffins

$\times$ Alkenes

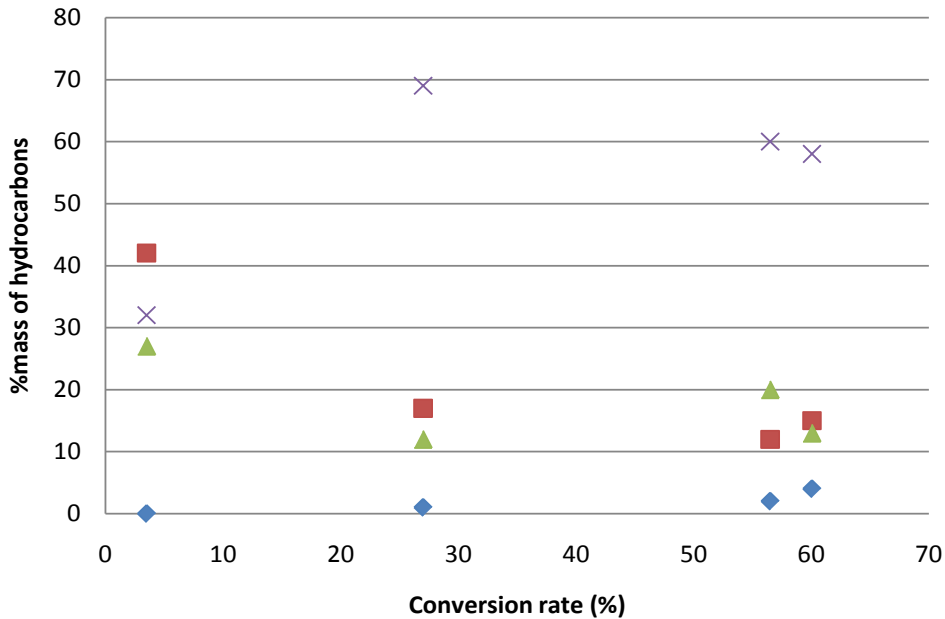

Styrenes

Alkybezenes

$\triangle$ Paraffins

$\times$ Alkenes

Figure 2. Representation of the proportions of the hydrocarbons as a function of reactions rate.

Table 7. Evolution of the mass proportions of the compounds according to the conversion rate.

\begin{tabular}{ccccccc}
\hline $\begin{array}{c}\text { Temperature } \\
\left({ }^{\circ} \mathrm{C}\right)\end{array}$ & $\begin{array}{c}\text { Styrenes } \\
(\text { Groundnut })\end{array}$ & $\begin{array}{c}\text { Alkylb } \\
(\text { Groundnut })\end{array}$ & $\begin{array}{c}\text { Styrenes } \\
(\text { Copra })\end{array}$ & $\begin{array}{c}\text { Alkylb } \\
(\text { Copra })\end{array}$ & $\begin{array}{c}\text { Styrenes } \\
(\text { Palm })\end{array}$ & $\begin{array}{c}\text { Alkylb } \\
(\text { Palm })\end{array}$ \\
\hline 400 & 0 & & 0 & 1.4 & 0 & 1.4 \\
450 & 0.4 & 0.6 & 0.2 & 1.7 & 0 & 2.6 \\
475 & 0.4 & 1 & 0.4 & 2.4 & 0.15 & 3 \\
500 & 0.4 & 3 & 0.5 & 3.1 & 0.4 & 4 \\
530 & - & - & 1.2 & 4 & 1.4 & 7 \\
550 & - & - & - & - & 2 & 8.6 \\
600 & - & - & - & - & 3.5 & 12.4
\end{tabular}

feedstock does not affect the proportions of the gum precursors. Water, on the other hand, permits to remarkably reduce the proportion of these unconjugated 


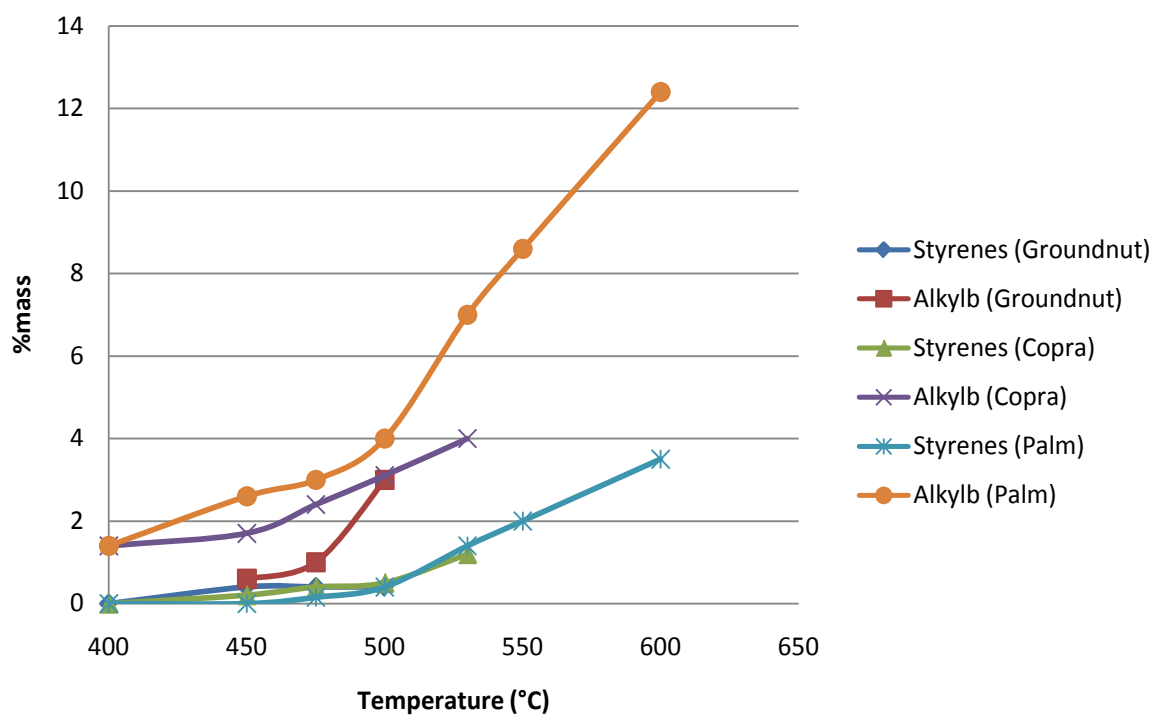

Figure 3. Distribution of the proportions of alkylbenzenes and styrenes as a function of temperature.

pi binding carriers, especially when the temperatures exceed $500^{\circ} \mathrm{C}$.

The results show that pyrolysis produced from $500^{\circ} \mathrm{C}$ contain coke precursors such as aromatics and styrene which are detrimental to the fuel formulation. These results are consistent with those of Lu Qiang et al. [16] who emphasize that the presence of cyclic aromatic hydrocarbons in the reactor effluent requires a lot of attention due to their carcinogenic properties.

The addition of methylcyclohexane only leads to the formation of branched paraffins. The n-paraffins are thus transformed to give compounds which give the hydrocarbon cut a good stability in the liquid phase.

The methylcyclohexane used as a hydrogen donor effectively reduces the proportion of coke.

This result is consistent with previous studies conducted by Doronin et al. [9] who cracked mixtures of hydrocarbons (cyclohexane, methylcyclohexane, and naphthenic hydrocarbons) either with oleic or stearic acids. They confirmed the role of hydrogen donor methylcyclohexane in their work.

\section{4) Influence of temperature}

The study of the influence of temperature on the conversion rates, graphs drawn on Figure 4 gives the evolution according to each oil.

As a first approximation, the conversion rates would evolve linearly with the temperature for each oil.

In a comparative analysis between oil, from $400^{\circ} \mathrm{C}$ to $475^{\circ} \mathrm{C}$, we have respectively in order of increasing conversion rate, groundnut oil, palm oil and copra oil. There would be a correlation between the conversion rate and the molar mass of the oil since oil of groundnut is heavier than the palm one which is heavier than the copra one. Above $475^{\circ} \mathrm{C}$, the trends of the curves show an inversion placing the groundnut more reactive than the palm which is in turn 


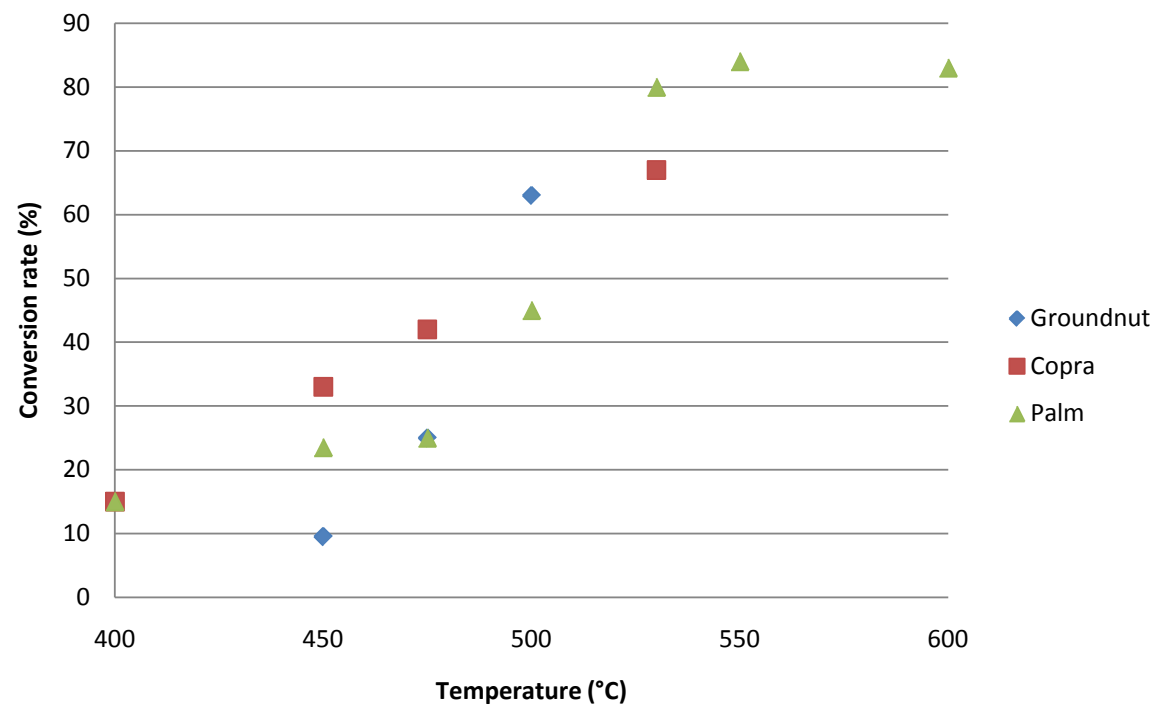

Figure 4. Evolution of conversion rates according to the temperature.

more than the copra. This justifies the fact that the latter favors more recombination of esters [3] than palm oil and groundnut oil. That is why Taufiqqurrahmi et al. [17] reported that the product quality is highly dependent on the type of vegetable oil used.

When extrapolating the evolutionary curves of the conversion rates as a function of temperature, we obtain for palm oil a plateau around $550^{\circ} \mathrm{C}$. This result is perfectly in agreement with those of our previous tests [3] which confirmed that the maximum rate during pyrolysis is reached for a temperature close to $550^{\circ} \mathrm{C}$. For this palm oil the limit conversion rate is $90 \%$.

\section{Conclusions}

During the pyrolysis of the oils, the rate of gas, especially hydrocarbon, must be reduced in order to minimize the loss of energy to the condensed organic phase. When temperatures are high, poly-alkenes react with alkyl benzenes to effect electrophilic polymerization to give unsaturated aromatics, including styrene, which are responsible for cokes. The production of coke plays against the possible industrialization of the pyrolysis due to a high frequency of maintenance of the organs of the unit.

Polyolefins are formed. They rapidly polymerize to form gum, causing the many problems encountered during our first trials of the use of crude oils as a diesel substitute fuel.

The polyolefins, with a proportion of about $30 \%$, could be used for the synthesis of long chain alkyl benzenes (detergents or surfactants) by acid-catalyzed pyrolysis.

An interesting route would therefore be to make the pyrolysis a water-dieseloil emulsion which could give interesting results, since the formation of coke would be inhibited to the maximum in this emulsion. This would benefit both the properties of the water and those of the petroleum derivative. 


\section{Acknowledgements}

The authors thank the CNRS and the french-ivoirian office for cooperation of the MAE for financial support.

\section{Conflict of Interest}

The authors declare no conflict of interest.

\section{References}

[1] Abollé, A., Kouakou, L. and Planche, H. (2009) The Viscosity of Diesel Oil and Mixtures with Straight Vegetable Oils: Palm, Cabbage Palm, Cotton, Groundnut, Copra and Sunflower. Biomass and Bioenergy, 33, 1116-1121. https://doi.org/10.1016/j.biombioe.2008.01.012

[2] Abollé, A., Kouakou, L. and Planche, H. (2009) The Density and Cloud Point of Diesel Oil and Mixtures with Straight Vegetable Oils (SVO): Palm, Cabbage Palm, Cotton, Groundnut, Copra and Sunflower. Biomass and Bioenergy, 33, 1653-1659. https://doi.org/10.1016/j.biombioe.2009.08.008

[3] Abollé, A., Planche, H., Trokourey, A. and Gossan, A. (2017) Pyrolysis of Water-in-Oil Emulsions and Vegetable Oils in the Presence of Methylcyclohexane, Analysed by GC/MS. International Journal of Scientific Engineering and Technology Research (IJETR), 7, 2454-4698.

[4] Singh, H.K.A/PG., Yusup, S. and Wai, C.K. (2016) Physicochemical Properties of Crude Rubber Oil for Biogasoline Production. Procedia Engineering, 148, 426-431. https://doi.org/10.1016/j.proeng.2016.06.441

[5] Kouassi, K.E. (2017) Optimisation de la transestérification des huiles végétales à des fins de carburant par des plans d'expériences et des réseaux de neurones artificiels couples à l'algorithme génétique. Thèse de Doctorat, Université Nangui Abrogoua, Abidjan, 183 p.

[6] Mailhe, A. (1922) Catalytic Decomposition of Shark Oil. Bulletin de la Société Chimique de France, 31, 249A.

[7] Lorant, B. (1972) Differential Thermal Analyses. Vol. 2, Édité par R.C. Mackenzie, Academic Press, New York.

[8] Gusmao, J., Brodzki, D., Mariadassou, D. and Frety, R. (1989) Utilization of Vegetable Oils as an Alternative Source for Diesel-Type Fuel: Hydrocracking on Reduced $\mathrm{Ni} / \mathrm{SiO}_{2}$ and Sulphided $\mathrm{Ni}-\mathrm{Mo} / \gamma-\mathrm{Al}_{2} \mathrm{O}_{3}$. Catalysis Today, 5, 533-544. https://doi.org/10.1016/0920-5861(89)80017-3

[9] Doronin, V.P., Lipin, P.V., Potapenko, O.V., Arbuzov, A.B. and Sorokina, T.P. (2016) Features of Combined Conversion of Naphthenic Hydrocarbons and Fatty Acids under Catalytic Cracking Conditions. Petroleum Chemistry, 56, 745-752. https://doi.org/10.1134/S096554411608003X

[10] Ikura, M., Stanciulescu, M. and Hogan, E. (2003) Emulsification of Pyrolysis Derived Bio-Oil in Diesel Fuel. Biomass and Bioenergy, 24, 221-232. https://doi.org/10.1016/S0961-9534(02)00131-9

[11] Abollé, A. (2016) Contribution à la valorisation des huilesvégétalesencarburants. Thèsed' Etat, Université Félix Houphouet-Boigny de Cocody, Abidjan.

[12] Bridgwater, A.V. (2012) Review of Fast Pyrolysis of Biomass and Product Upgrading. Biomass and Bioenergy, 38, 68-94. https://doi.org/10.1016/j.biombioe.2011.01.048

[13] French, R. and Czernik, S. (2010) Catalytic Pyrolysis of Biomass for Biofuel Produc- 
tion. Fuel Processing Technology, 91, 25-32.

https://doi.org/10.1016/j.fuproc.2009.08.011

[14] Hossain, A.K., Ouadi, M., Siddiqui, S.U., Yang, Y., Brammer, J., Hornung, A., Kay, M. and Davies, P.A. (2013) Experimental Investigation of Performance, Emission and Combustion Characteristics of an Indirect Injection Multi-Cylinder CI Engine Fueled by Blends De-Inking Sludge Pyrolysis Oil with Biodiesel. Fuel, 105, 135-142. https://doi.org/10.1016/j.fuel.2012.05.007

[15] Zhu, C.-C. Ren, C., Tan, X.-C. Chen, G., Yuan, P.-Q., Cheng, Z.-M. and Yuan, W.-K. (2013) Initiated Pyrolysis of Heavy Oil in the Presence of Near-Critical Water. Fuel Processing Technology, 111, 111-117. https://doi.org/10.1016/j.fuproc.2013.02.003

[16] Lu, Q., Li, W.-Z. and Zhu, X.-F. (2009) Overview of Fuel Properties of Biomass Fast Pyrolysis Oils. Energy Conversion and Management, 50, 1376-1383. https://doi.org/10.1016/j.enconman.2009.01.001

[17] Taufiqqurrahmi, N. and Bhatia, S. (2011) Catalytic Cracking of Edible and Non Edibleoils for the Productions of Biofuel. Energy and Environmental Science, 4, 1087-1112. https://doi.org/10.1039/c0ee00460j 